\title{
THREE-DIMENSIONAL FINITE-ELEMENT SIMULATION OF HOT RING ROLLING.
}

\author{
J. Huez, J-L. Noyes and J. Coupu* \\ FORTECH \\ BP 173 - 09102 PAMIERS cedex - FRANCE \\ * IRSID (Usinor group) \\ BP 30320 - 57283 MAIZIERES LES METZ cedex - FRANCE
}

\begin{abstract}
A model was developed to investigate the hot ring rolling process taking into account the radial and axial rolling tools.

Each ring revolution is divided into four separates steps where thermal and thermal/mechanical simulations are alternated.

The material flow in the deformation zone, taking into account the three dimensional inhomogeneous deformation, is analyzed in steady state conditions, whilst the heat transter outside of the roll-bite region is analyzed by an axis-symmetric non steady state F.E.M. formulation.

Due to its acceptable computational cost, the model is applied to predict the temperature, strain and strain rate evolution necessary for the structure forecast of an industrial ring rolling process.
\end{abstract}


Ring rolling is a specified rolling process used to produce seamless rings by reducing the cross section and increasing the diameter of ring blanks between rotating rolls. Compression between a idler roll and a main roll cause the ring to grow; compression also takes place in the axial direction between edging rolls (figure 1).

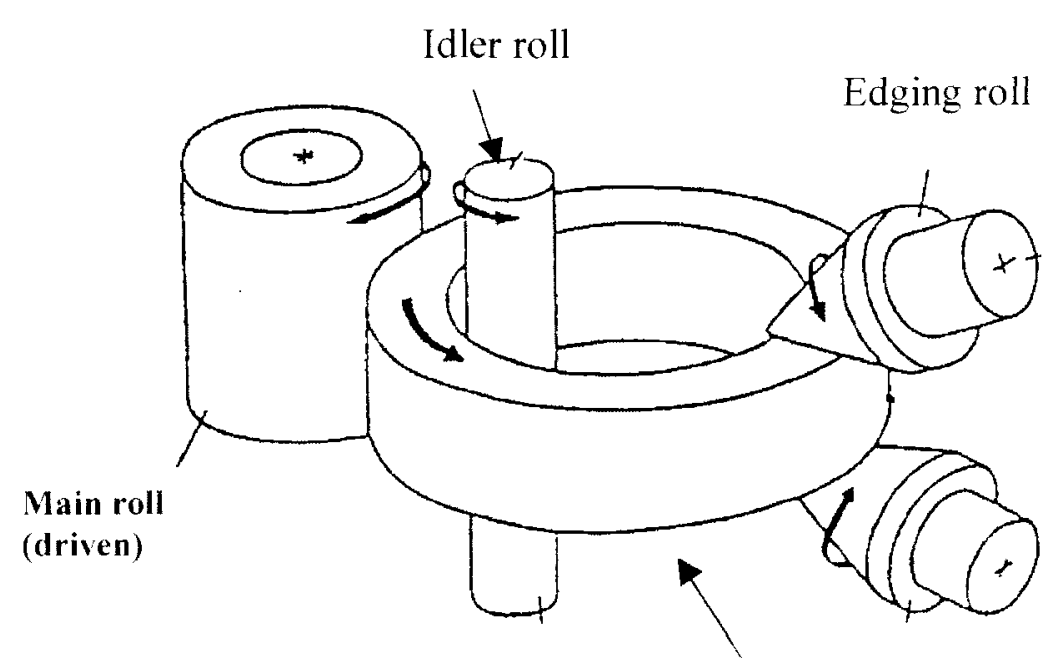

Figure 1 : Ring rolling process

Workpiece

Ring rolling is applied essentially in spacecraft and engine aerospace applications. The technique enables the production of a wide ring product range: ring from $300 \mathrm{~mm}$ to 8 meters of diameters could be produced at Dembiermont [1] from titanium, aluminum and copper alloys, steel and nickel base superalloys.

This process offers the advantage in a short production time to reach desirable mechanical properties with good surface quality and saves material costs.

During ring rolling, the material is subjected to complex temperature-time-strain rate histories with important consequences on the microstructure and thus on the final product mechanical properties. It appears to be necessary to have a better comprehension of the influence of all process parameters on such microstructural evolution in order to optimize them and to make ring rolling a reliable process.

Computer simulation of the process allows us to know strain, stress and temperature distribution in the ring and provides a means of process control of microstructures and properties of commercial products.

But if a lot of work has been done on the simulation of flat or long product rolling [2], only certain aspects of the ring rolling process have been studied [3]. It appears that the essential problem in the simulation of the ring rolling process via the finite element method is of run time. Run time is a particular issue in ring rolling due to the large number of revolutions of the ring. The problem involves several times the number of increments required to simulate other metal forming processes.

In the present study, we will present and discuss results of ring rolling process simulation obtained using a model developed in collaboration with the IRSID. 


\section{Modelling}

\section{Finite element model}

The model detailed elsewhere [4] is presented here briefly.

Based on the 3D F.E.M. software LAM3 [5], dedicated to flat and long products rolling, a ring rolling modulus has been developed in collaboration between Fortech and IRSID.

The model is based on the hypothesis that a full ring mesh analysis is not required in major ring rolling configuration : it consists of having a $3 \mathrm{D}$ finite element simulation in the roll gap only and a $2 \mathrm{D}$ in the inter-pass time.

Only a part of the ring is treated in the deformation zone and outside the roll bite region as it is shown in figure 2. One half of the ring segment is described due to vertical plan symmetry. Finer elements in the deformation zone provide more accurate results.

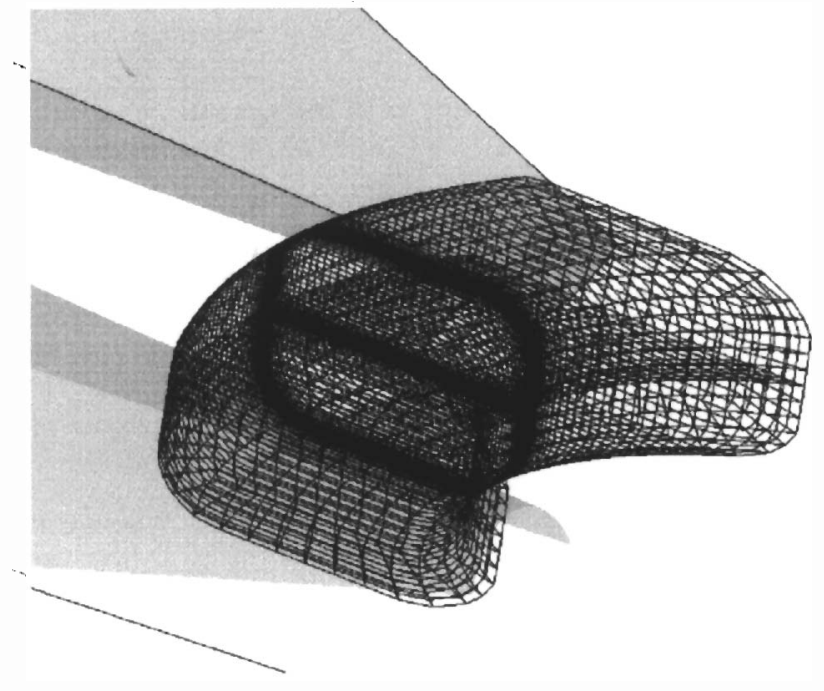

a)

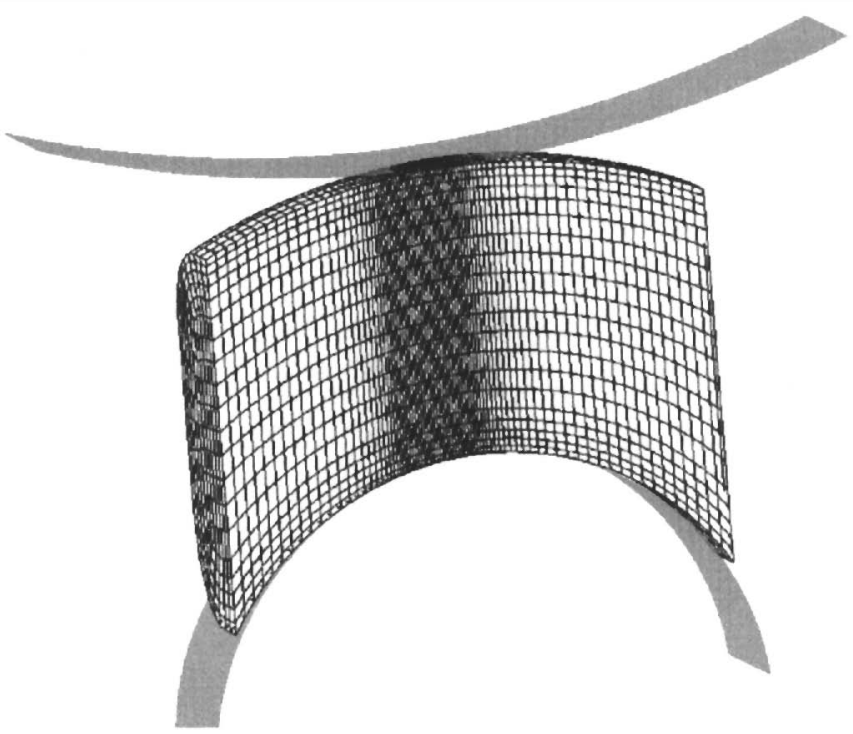

b)

Figure 2: Mesh used for computations. a) axial bite, b) radial bite (half cross section is presented).

The analysis of the process is a succession of revolution, each revolution consisting of four different calculations (figure 3 ):

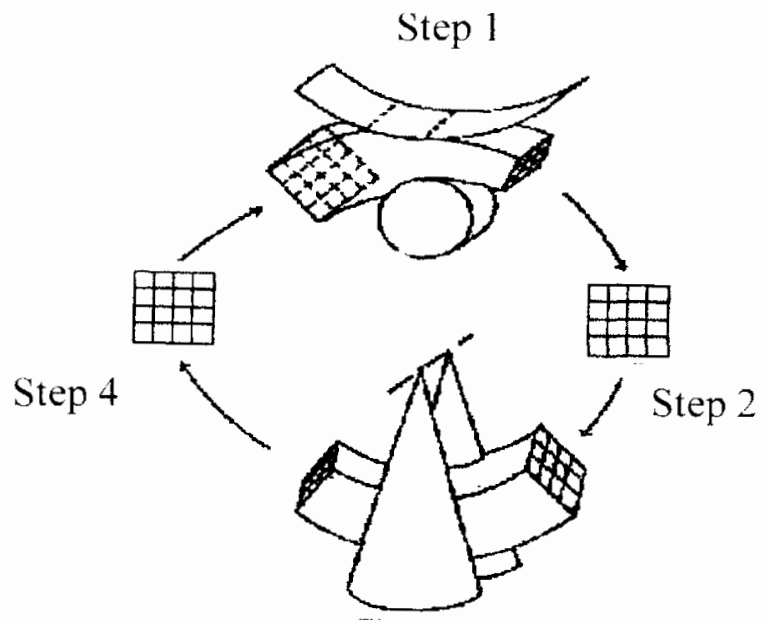

Step 3

Figure 3 : Description of the four steps of calculation. 
Zone 1 and 3 : calculation of the plastic flow in the radial and axial bite. The reduction of thickness or height is applied. The thickness reduction for each revolution is generally less than $5 \%$. For the thermomechanical analysis of the ring rolling, the dissipated friction power is negligible compared to the dissipated deformation power.

For the radial and axial roll bites modelling. the steady state formulation uses a streamline formulation. Both free surface and internal nodes ensure that lines of nodes are located on streamlines.

Zone 2 and 4 : outside deformation zones. For the simulation of these zones, a Lagrangien unsteady state formulation is used.

The diameter growth due to the previous deformation into the bite is applied at this step.

The temperature evolution is calculated at each step of the revolution. taking into account the contact with tools when it exists.

The thermal constants are determined such as calorific capacity, thermal conductivity. emissivity and the global transfer coefticient : the heat transfer coefficients between tools and workpiece and exterior area interface. Losses by radiation and convection are taken into account as are conduction effects and adiabatic heating produced during deformation.

The evolution of the temperature has been validated using thermocouple instrumentation on an industrial ring rolling [4]. A good match exists between predicted and experimental values, confirming the well adjusted value of interfacial and thermophysical properties of the material introduced.

Concerning the constitutive law, a visco-plastic rheology associated to Hill vield criterion and Coulomb friction law were used for calculation.

\section{General application}

We simulate a classical axial-radial rolling of an Inconel 718 ring, using data recorded during the effective industrial ring rolling to improve the capability and the reliability of the model. The aim of this investigation is to determine the strain and temperature distribution along the cross section of a ring over the entire rolling process.

\section{Material}

The chemical composition of alloy 718 used in this investigation is given in Table 1 .

Table I : Chemistry of alloy 718 used. Weight percentage.

\begin{tabular}{|c|c|c|c|c|c|c|c|}
\hline $\mathrm{Ni}$ & $\mathrm{Fe}$ & $\mathrm{Cr}$ & $\mathrm{Nb}$ & $\mathrm{Ti}+\mathrm{Al}$ & $\mathrm{Mo}$ & $\mathrm{Mn}$ & $\mathrm{C}$ \\
\hline 53.75 & 18.14 & 17.95 & 5.41 & 1.48 & 2.84 & 0.05 & 0.024 \\
\hline
\end{tabular}

The microstructure of alloy 718 is governed by the fcc lattice of the $\gamma$ matrix associated with characteristic precipitates such as the niobium rich $\gamma$ " phase. The presence of this precipitate is the essential strengthening mechanism in this alloy. $\gamma$ " will transform to a stable orthorhombic $\delta$ phase during elevated temperature exposure.

The alloy 718 is double melted : the primary melting is a vacuum Induction melting (VIM). followed by an Vacuum Arc Remelting (VAR). Grain size of ASTM 7 is obtained after billetizing. 
The transformation process consists firstly in an upsetting followed by a punching in order to obtain, after removal of the bore, a ring with the dimensions indicated on figure 4a.

The second step of the process is ring rolling to obtain a ring of rectangular cross section (figure 4b). The ring rolling process takes $190 \mathrm{~s}$, corresponding to 40 revolutions.

a)

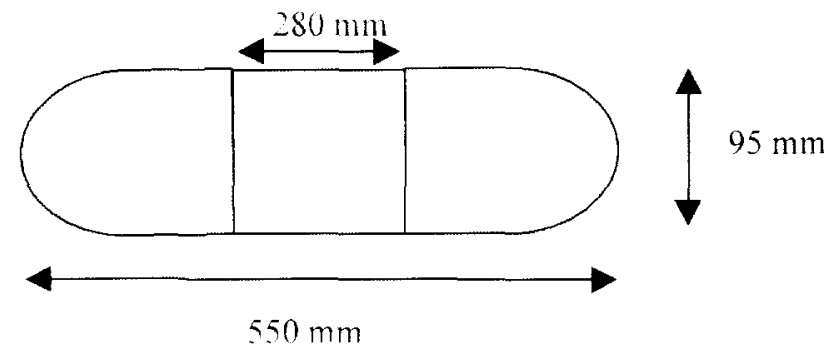

b)

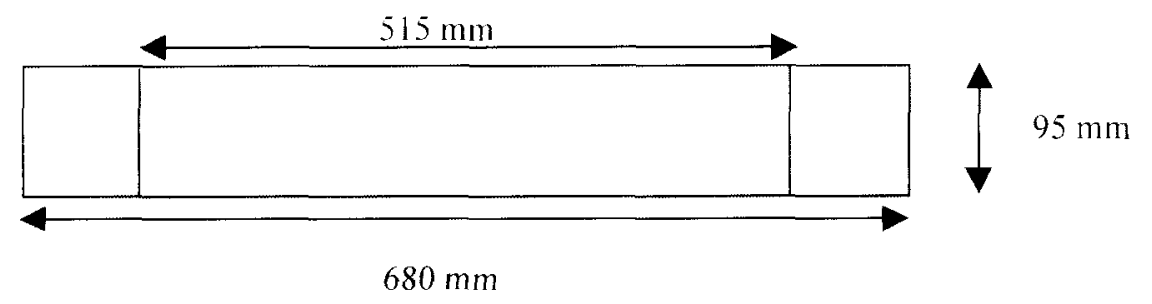

Figure 4 : Initial (a) and final (b) ring dimensions

During ring rolling, data such as the radial and axial efforts, but also the evolution of the different dimensions of the ring and the speed of the motor are registered.

After ring rolling, a section of the part is machined and polished to observe the microstructure. At the same time, the simulation of this part is carried out and we analyze the temperature and strain evolution in this multi-pass ring rolling process and the consequences on the microstructure.

\section{$\underline{\text { Simulation results and microstructure observation }}$}

A $2 \mathrm{D}$ mesh with the initial section of the ring is produced. Then the $3 \mathrm{D}$ mesh used for the outside roll and for the deformation zones are generated. The dimension of the tools used for this calculation are :

Main roll : $1140 \mathrm{~mm}$ diameter

Idler roll : $275 \mathrm{~mm}$ diameter.

Edging roll : $35^{\circ}$ angle

The initial rotation speed of main roll is $1 \mathrm{rd} / \mathrm{s}$

The initial temperature of the Idler roll is $80^{\circ} \mathrm{C}$ and that of the furnace $1000^{\circ} \mathrm{C}$.

1) The simulation starts by a thermal calculation corresponding to the transport time from furnace to ring rolling mill : a transport time of $40 \mathrm{~s}$ is assumed. 
2) Following the section reduction registered (a mean value of the section reduction made during a revolution is applied) the first thermomechanical calculation into the radial rolls runs. The effort distribution between the main and the idler roll is calculated. The tool positions are readjusted by an iterative scheme to obtain an equilibrium between the two rolling efforts. The main roll is the driving mechanism in the simulation as in the industrial process. The speed of the edging rolls are updated to reduce the lateral deviations of the ring measured at the front and back of the radial bite. For this simulation, the speed is regulated in function of the radial speed of the ring diameter and the corresponding axial roll radius. During the tirst rolling passes, the radial thickness reduction per pass is small, due to the high angular rolling speed.

Figure 5 shows the temperature distribution along the half cross section, for various step of the simulation.

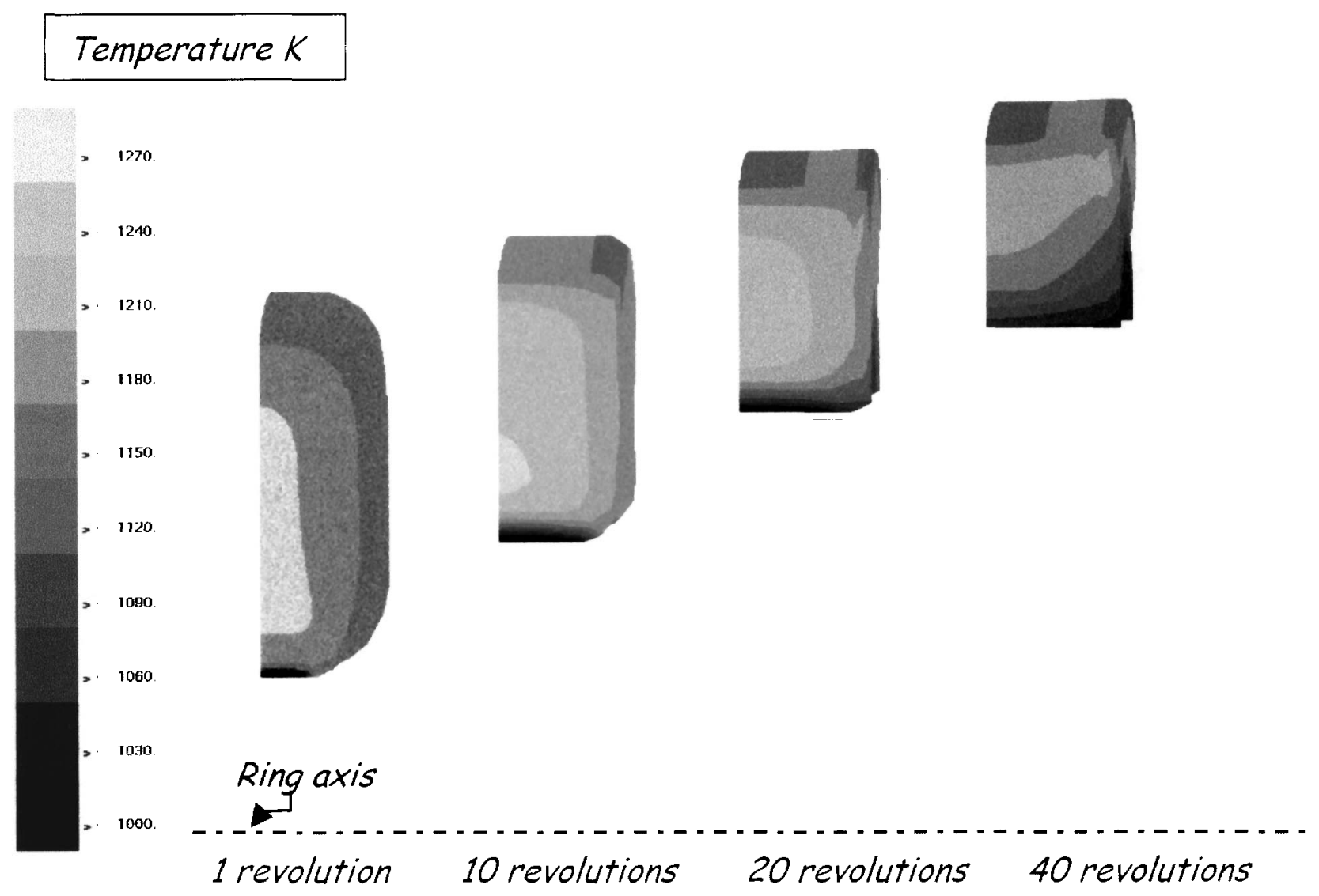

Figure 5: Temperature map on the ring cross section during rolling (Temperature is given in Kelvin).

In the radial bite, at the beginning, the temperature is higher in the inner ring surface, which could be explained by less heat loss by radiation, but as the rolling is run, the temperature of the inner surface of the ring decreases due to a higher contact surface. During ring rolling, the center of the ring retains a high temperature but can also increase it, due to the addition of forming energy.

Concerning the deformation distribution in the radial bite, the strain is low in the center of the ring and higher near the inner and outer radii. The strain level per pass is weak, around 0.01 and 0.08 for the maximum (figure 6 ).

The simulation shows clearly the edge drop formation on the upper and lower surfaces of the ring (see figure 5, 40 revolutions). 

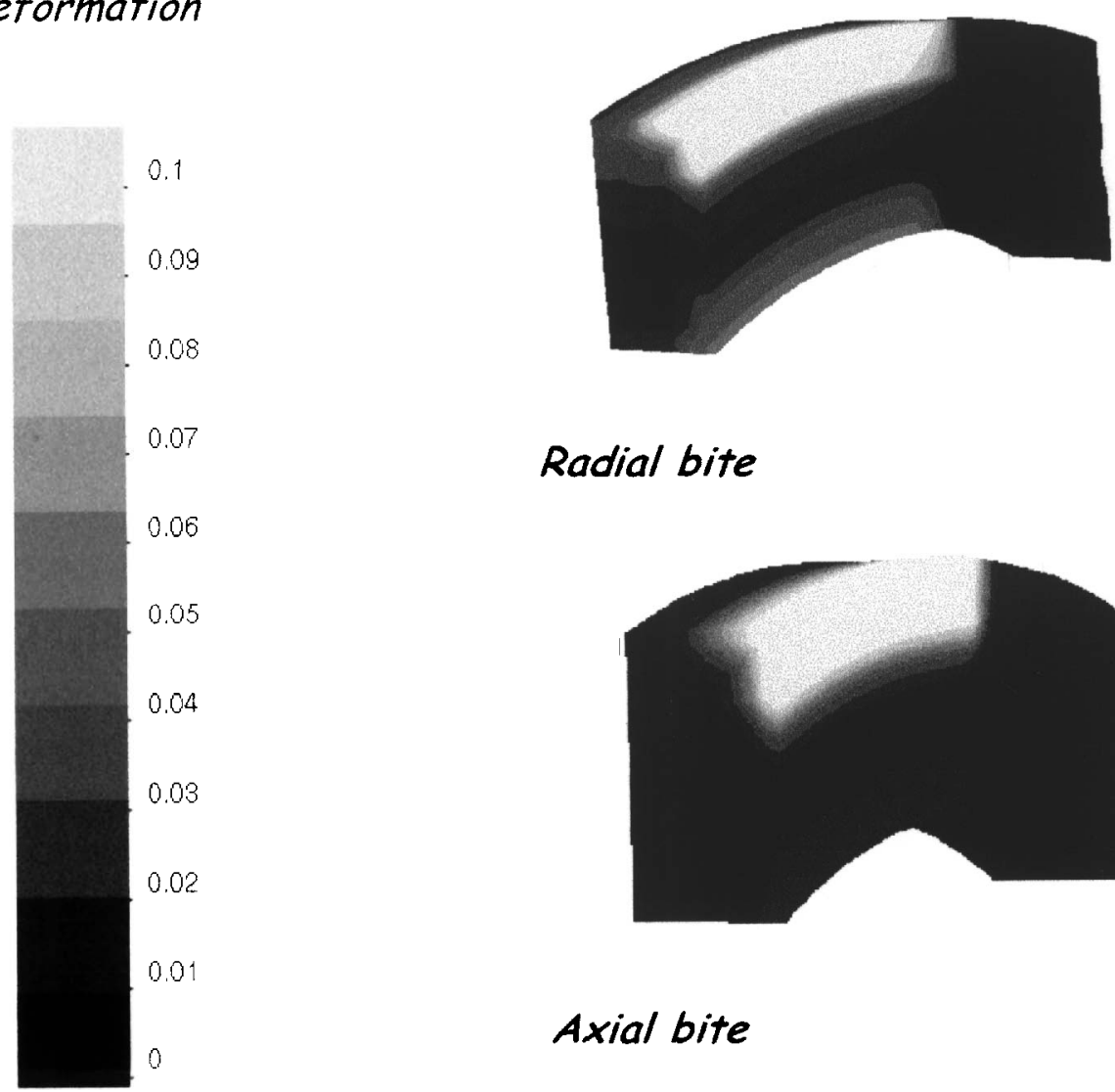

\section{Radial bite}

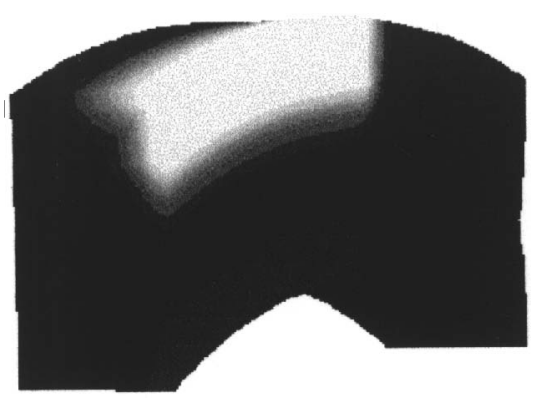

Axial bite

Figure 6: Deformation level per pass in each deformation zone (half cross section).

3) During the inter-pass time, the temperature evolution is calculated, and the increase of diameter due to the previous deformation is applied.

The duration of inter-pass is too short to initiate grain growth, but probably allows local dynamic recrystallization to occur.

4) In the axial bite, we can confirm that the ring rolling process has localized contact conditions: local plastic deformation appears at the corners, due to the reduced edge drop (figure 6), so the cumulate strain distribution will be heterogeneous after 20 revolutions (figure 7). The corners which were initially colder became warmer than the center. An important deformation gradient is revealed at this step (deformation between 0.5 in the center and 1.4 on the surface, see figure 7). 


\section{Deformation}

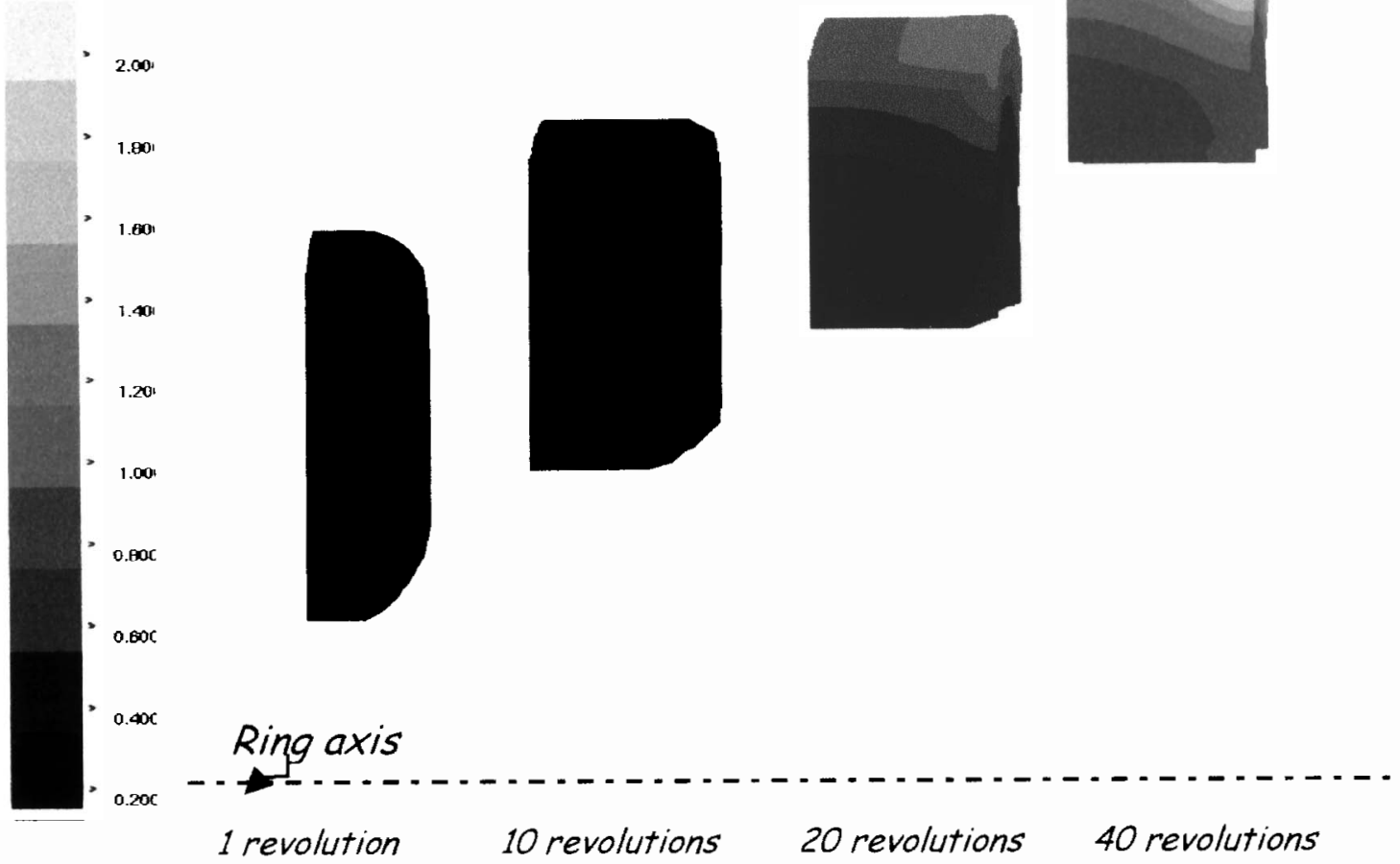

Figure 7 : Cumulated deformation map at different step during rolling.

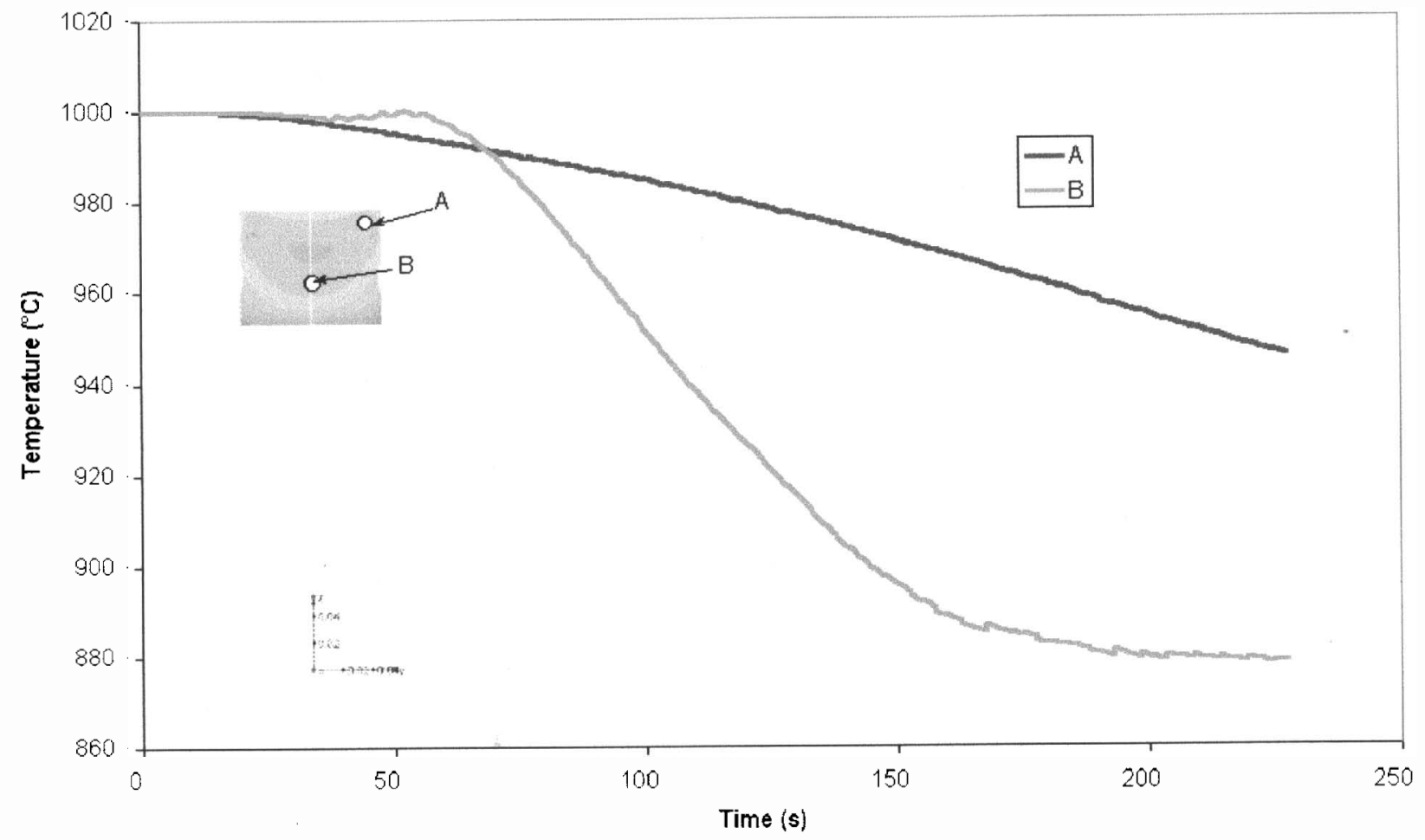

Figure 8 : 'lemperature evolution over time during rolling 
The final geometry of the simulated ring corresponds with that of the industrial ring confirming that the material flow occuring in the ring is well simulated. The input data used in the simulation is well adapted as is the rheology.

From the simulation it is also possible to follow the temperature and the strain during the entire process. Figure 8 shows that on this ring : a good homogeneous distribution of temperature is observed during transport time ; during rolling, the temperature evolution is affected by the work plastic deformation as well as contact with the tools. The center temperature increases to a maximum of $1005^{\circ} \mathrm{C}$ during the first revolution and falls to $890^{\circ} \mathrm{C}$ at the end of the process, whereas the corner temperature, decreasing during all the process, remains at an elevated temperature of $960^{\circ} \mathrm{C}$.

The observation of the final ring cross section is in concordance with these results. Two zones are distinguished (tigure 9):

- the center of the ring presents an homogeneous microstructure with a grain size of ASTM 10. The grains are recovered ; at high magnitication, twins are visible.

- a peripheric zone presenting various microstructures depending on the temperature and deformation histories. The inner and outer volume of the ring is a mix of strained and recrystallized grains, recrystallization being more or less advanced. The corner corresponding to the inner radius is deformed with a beginning of recristallization. This is due to the phenomen of edge drop, this zone being continously deformed and flattened during ring rolling.

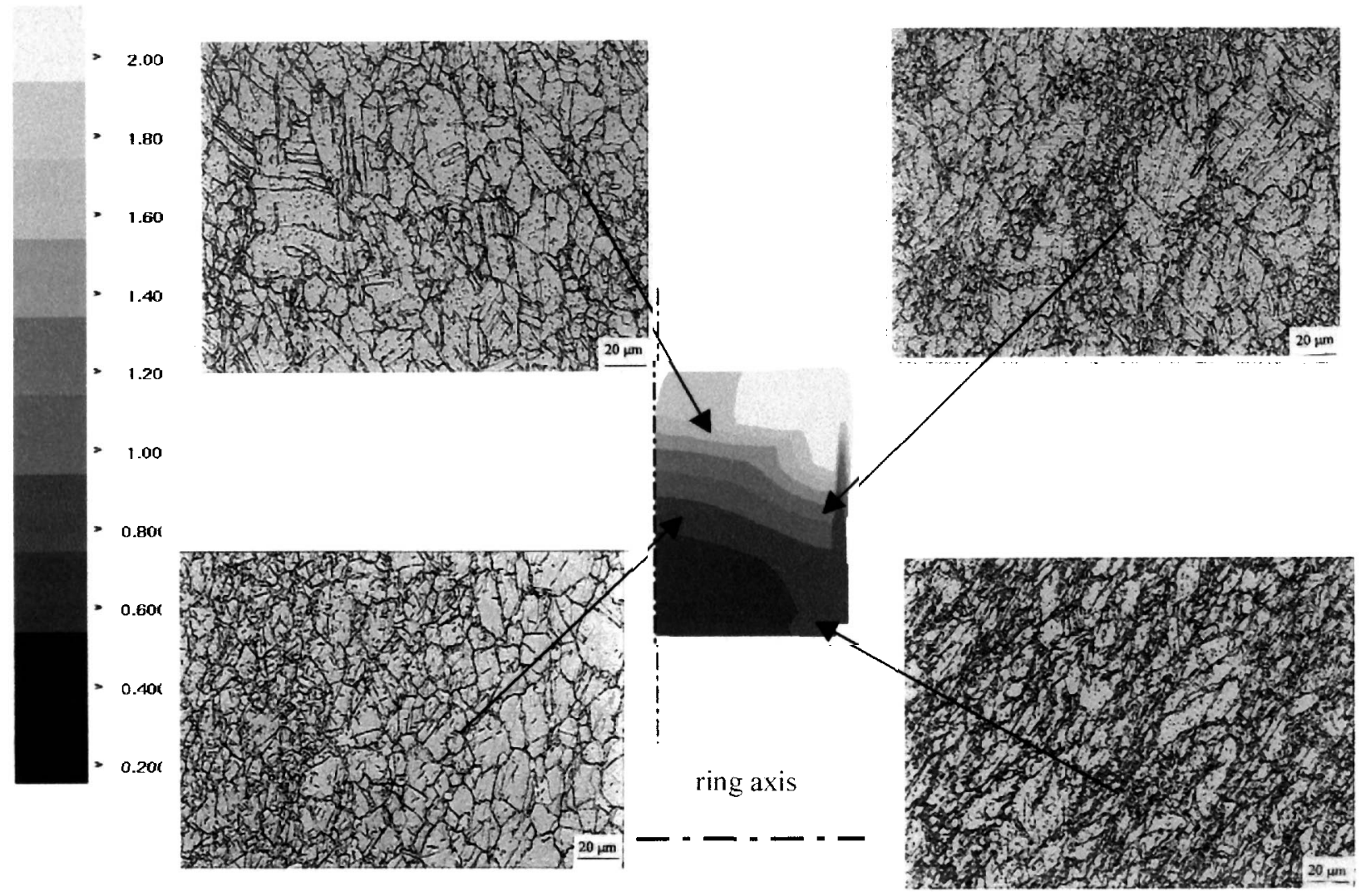

figure 9 : location of the final microstructures observed compare to the final strain map. 
The model developed by Irsid gives accurate results and offers the possibility to optimize the operation of ring rolling. Now we dispose of the simulation of all the different metal forming processes, allowing us to understand better the influence of one or the other thermal/mechanical parameters on the microstructure of the final product.

Concerning the simulation presented above: the time computation taken on a alpha600 workstation was still relatively long, around 5 hours for one roll bite at any revolution. But in this case. we were confronted by a compact ring having its inner diameter very similar to the idler roll diameter, this, making it necessary to carry out converging calculations in order to optimize the position of the entry section giving the equilibrium efforts of the idler and main rolls. This location defines the correct reduction due to each roll, but doubles the calculation time. Many ring configurations do not require this operation if the inner radius is $>$ to 3 thickness.

\section{Conclusion}

The operation of ring rolling was investigated via a FEM based model, developed to simulate the temperature and strain distribution inside the ring throughout the forming process. Validated, this model allows a more precise estimation and control of microstructure changes occuring during metal forming but also helps to appreciate the influence of parameters such as the rolling speed or the reduction per pass for example.

From this study it appears that axial rolling effect must be taken into account for the prediction of the temperature and strain evolution, especially near the corners of the ring where alternative edge drop is created.

The mesh, used with enough elements to simulate the material flow properly, requires acceptable time computation due to the steady state analysis of the deformation zones.

[1] http://www. dembiermont.com

[2] Jaiswal S. and Howe AA, "Progress and issues in modelling of hot deformation and microstructure evolution for steel products », $1^{\text {st }}$ Intenational Conference on Metal Rolling Processes (London), ppl 16-133, 1993.

[3] Yang DY., Kim KH. and Hawkyard JB, « Simulation of T-section profile ring rolling by 3D rigid plastic Finite Element Method », Int. J. Mech. Sci. Vol 33, N 7, pp 541-550, 1991.

[4] Coupu J., Raulin JL., and Huez J., « Investigation of hot ring rolling using 3D finite element simulation ». Modelling of Metal Rolling. Processes 3. (London), 1999.

[5] L AM3 Software: Transvalor - I.es Espaces Delta - BP 037-06901 Sophia Antipolis France. 